\title{
APLIKASI AMINOETHOXYVINYLGLYCINE (AVG), PLASTIC WRAPPING DAN SUHU SIMPAN UNTUK MENINGKATKAN MASA SIMPAN DAN MEMPERTAHANKAN MUTU BUAH JAMBU BIJI 'CRYSTAL'
}

\author{
Soesiladi Esti Widodo, Zulferiyenni \& Riska Agustine \\ Jurusan Agroteknologi, Fakultas Pertanian Universitas Lampung \\ J1. Prof. Soemantri Brodjonegoro, No.1 Bandar Lampung 35145 \\ E-mail: sestiwidodo@gmail.com
}

\begin{abstract}
ABSTRAK
Jambu biji 'Crystal' memiliki masa simpan yang singkat dan mudah mengalami kerusakan. Masa simpan buah jambu biji 'Crystal' hanya berkisar 2 - 7 hari. Upaya pascapanen yang dapat dilakukan untuk meningkatkan masa simpan adalah dengan aplikasi Aminoethoxyvinylglycine (AVG), pengemasan dengan plastic wrapping, dan penyimpanan suhu rendah. Penelitian ini bertujuan untuk mengetahui pengaruh aplikasi AVG, plastic wrapping, suhu simpan, dan interaksi antara aplikasi AVG, plastic wrapping dan suhu simpan terhadap masa simpan dan mutu buah jambu biji 'Crystal'. Penelitian ini dilaksanakan di Laboratorium Pascapanen Hortikultura, Fakultas Pertanian, Universitas Lampung pada bulan September - Oktober 2014. Penelitian ini menggunakan Rancangan Teracak Sempurna (RTS) dengan tiga ulangan. Rancangan penelitian ini disusun secara faktorial $2 \times 2 \times 2$. Faktor pertama adalah AVG (dengan dan tanpa AVG), faktor kedua adalah plastic wrapping (dengan dan tanpa plastic wrapping), faktor ketiga adalah suhu simpan (suhu ruang $26,87^{\circ} \mathrm{C}$ dan suhu rendah $21,53{ }^{\circ} \mathrm{C}$ ). Hasil penelitian menunjukkan bahwa aplikasi AVG tidak mampu meningkatkan masa simpan, kekerasan, susut bobot, ${ }^{\circ} \mathrm{Brix}$, asam bebas, dan kemanisan pada buah jambu biji 'Crystal'. Aplikasi plastic wrapping mampu menekan susut bobot, tetapi tidak mampu meningkatkan masa simpan, mempertahankan kekerasan, ${ }^{\circ}$ Brix, asam bebas, dan tingkat kemanisan buah jambu biji 'Crystal'. Penyimpanan suhu rendah tidak mampu meningkatkan masa simpan, kekerasan, susut bobot, ${ }^{\circ}$ Brix, asam bebas, dan kemanisan pada buah jambu biji 'Crystal' dan tidak terdapat interaksi antara AVG, plastic wrapping dan suhu rendah dalam meningkatkan masa simpan dan mempertahankan kekerasan, susut bobot, ${ }^{\circ}$ Brix, asam bebas, dan kemanisan pada buah jambu biji 'Crystal'.
\end{abstract}

Kata kunci: Aminoethoxyvinylglycine, jambu biji, plastic wrapping, suhu simpan

\section{PENDAHULUAN}

Buah jambu biji 'Crystal' merupakan buah klimakterik. Buah klimakterik memiliki masa simpan yang singkat dan mudah mengalami kerusakan. Masa simpan buah jambu biji pada umumnya hanya berkisar antara 2 - 7 hari (Widodo et al., 2012). Apabila buah disimpan lebih dari 7 hari, maka terdapat bercak coklat pada kulit buah, daging buah akan melembek, dan buah terlihat layu.

Masa simpan yang singkat menyebabkan perlunya penanganan pascapanen pada buah klimakterik, terutama buah jambu biji 'Crystal'. Salah satu cara yang dilakukan adalah dengan aplikasi aminoethoxivynilglycyine (AVG). Aplikasi AVG dipercaya dapat memutus produksi etilen pada suatu produk, sehingga masa simpan jambu biji dapat ditingkatkan. Hal ini diperkuat oleh penelitian Cetinbas dan Konyucu (2011) yang menjelaskan bahwa buah persik 'Monroe' dengan perlakuan AVG prapanen sebesar 100 atau 200 ppm dapat bertahan 4-6 hari lebih lama dibandingkan dengan perlakuan kontrol.

Buah jambu biji 'Crystal' memiliki kulit yang tipis sehingga laju transpirasi berjalan dengan sangat cepat. Laju transpirasi yang cepat akan menyebabkan buah kehilangan air dengan cepat sehingga akan memperburuk tampilan dan menurunkan mutu buah. Penambahan plastic wrapping atau plastik pelapis buah pada proses pascapanen telah diterapkan untuk beberapa buah, khususnya jambu biji. Hasil penelitian Widodo et al. (2013b) menunjukkan bahwa penggunaan plastic wrapping dapat mempertahankan mutu dan meningkatkan masa simpan buah jambu biji 'Mutiara' dan 'Crystal' selama 7-8 hari.

Penggunaan plastic wrapping menyebabkan peningkatan suhu pada buah. Peningkatan suhu disebabkan oleh proses respirasi pada saat buah disimpan yang menghasilkan energi dan $\mathrm{CO}_{2}$. Tindakan yang dilakukan untuk menjaga suhu agar tetap stabil adalah dengan cara penyimpanan pada suhu rendah. 
Suhu rendah akan mampu mempertahankan mutu buah yang erat kaitanya dengan penurunan laju respirasi pada suatu produk. Hasil penelitian Teixeira dan Durigan (2010) menyatakan bahwa suhu $12,5^{\circ} \mathrm{C}$ dengan kadar oksigen 1-5 kPa dapat meningkatkan masa simpan pada buah jambu biji 'Pedro Sato'.

Tujuan penelitian adalah mengetahui pengaruh aplikasi AVG, plastic wrapping, suhu simpan, dan interaksi antara AVG, plastic wrapping, dan suhu simpan terhadap masa simpan dan mutu buah jambu biji 'Crystal'.

\section{BAHAN DAN METODE}

Penelitian ini dilakukan di Laboratorium Pascapanen Hortikultura, Jurusan Agroteknologi, Fakultas Pertanian, Universitas Lampung pada bulan September-Oktober 2014. Bahan yang digunakan pada penelitian ini adalah buah jambu biji 'Crystal' stadium matang (mature) hijau pucat yang didapatkan dari PT. Nusantara Tropical Farm (PT. NTF) Way Jepara, Kabupaten Lampung Timur, plastic wrapping (Klin pak - Cling Wrap), aminoethoxyvinylglycine (AVG), aquades, fenolftalein dan $\mathrm{NaOH} 0,1 \mathrm{~N}$. Alat yang digunakan pada penelitian ini adalah timbangan, penetrometer, refraktometer-tangan 'Atago', biuret, erlenmeyer, labu ukur, sentrifus 'Heraus Sepatech', pipet tetes, pipet gondok/ pipet volumetrik, gelas ukur, gelas beker, botol sampel, tisu, koran , pisau, piring styrofoam, air conditioner (AC), dehumidifier, thermohygrograph, lemari es, dan blender.

Penelitian ini dilakukan dengan menggunakan Rancangan Teracak Sempurna (RTS) dengan tiga ulangan. Setiap ulangan terdiri atas satu buah jambu biji. Buah yang telah diberi perlakuan kemudian disimpan di dalam suhu ruang $\left(26,87^{\circ} \mathrm{C}\right)$ dan suhu rendah $(21,53$ $\left.{ }^{\circ} \mathrm{C}\right)$. Sebagai pembanding, 3 buah jambu biji diamati pada awal penelitian. Rancangan perlakuan disusun secara faktorial $2 \times 2 \times 2$. Faktor pertama adalah AVG: kontrol (tanpa AVG; A0) dan dengan AVG (5 mg/4 liter aquades AVG; A1). Faktor ke dua adalah plastic wrapping: kontrol (tanpa plastik wrapping ; PO) dan dengan plastic wrapping satu lapis (P1). Faktor ke tiga adalah suhu simpan: disimpan pada suhu ruang (T0) dan pada suhu rendah (T1).

Buah jambu biji 'Crystal' stadium matang (mature) hijau pucat disortasi berdasarkan ukuran (165220 gram) dan bentuk yang seragam untuk ke tahap selanjutnya. Penggunaan AVG dilakukan dengan melarutkan AVG murni (berbentuk serbuk), $5 \mathrm{mg}$ AVG dilarutkan dalam 4 liter aquades. AVG diaplikasikan dengan merendam buah jambu biji 'Crystal' selama 10 menit. Selanjutnya, buah dikeluarkan dari tempat perendaman tersebut lalu dikering-anginkan. Setelah kering-angin, buah yang diperlakukan dengan plastic wrapping dibungkus dengan plastic wrapping satu lapis. Setelah dilakukan pengemasan pada buah jambu biji 'Crystal', maka buah tersebut disimpan pada suhu simpan ruang dan suhu simpan rendah sesuai dengan perlakuan. Ruang suhu rendah $21,53^{\circ} \mathrm{C}$ yang digunakan berukuran $5,85 \times 2,85 \times 3,15 \mathrm{~m}$ dengan dua air conditioner (AC), satu dehumidifier dan satu thermohygrograph.

Pengamatan dilakukan sebelum penerapan perlakuan, yaitu pengukuran bobot buah dan pada saat akhir sampling buah. Pengamatan dihentikan apabila telah muncul bercak coklat (browning) atau keriput pada kulit buah. Peubah yang diamati adalah masa simpan, susut bobot buah, tingkat kekerasan buah, kandungan padatan terlatur ( ${ }^{\circ}$ Brix), total asam bebas, dan tingkat kemanisan buah jambu 'Crystal'.

\section{HASIL DAN PEMBAHASAN}

Masa simpan buah jambu biji 'Crystal' ditentukan secara fisik dan visual, yaitu pada saat buah telah menunjukkan kemerosotan mutu seperti terdapat bercak coklat (browning) dan keriput pada kulit buah. Buah jambu biji 'Crystal' dengan perlakuan aminoethoxyvinyglycine $\left(\mathrm{A}_{1}\right)$ tidak berpengaruh nyata dalam meningkatkan masa simpan dibandingkan tanpa AVG ( $\left.\mathrm{A}_{0}\right)$ (Tabel 1). AVG digunakan dengan tujuan untuk memutus produksi etilen pada buah sehingga dapat meningkatkan masa simpan dan mempertahankan mutu buah jambu biji 'Crystal'. AVG yang diaplikasikan pada buah jambu biji 'Crystal' stadium matang (mature) tidak mampu mempengaruhi masa simpan buah (Tabel 1). Hal ini diduga karena konsentrasi AVG 1,25 ppm masih rendah. Perlakuan AVG 30 ppm dan penyimpanan suhu dingin mampu menghambat biosintesis etilen pada buah pir 'Le Conte' sehingga dapat menunda pemasakan dan memperpanjang masa simpan buah dibandingkan tanpa AVG (Tarabih, 2014).

Pengemasan menggunakan plastic wrapping $\left(\mathrm{P}_{1}\right)$ tidak berbeda nyata dengan tanpa plastic wrapping $\left(\mathrm{P}_{0}\right)$ terhadap masa simpan (Tabel 1). Widodo et al. (2013a) menyatakan bahwa buah jambu biji 'Crystal' memiliki lapisan lilin alami pada permukaan kulit buahnya. Hal ini diduga menyebabkan pengemasan tidak berpengaruh nyata dalam meningkatkan masa simpan buah jambu biji 'Crystal'.

Penyimpanan suhu rendah juga dapat dilakukan untuk menghambat proses respirasi. Suhu rendah digunakan untuk menjaga suhu di dalam buah agar tetap 
Tabel 1. Pengaruh AVG, plastic wrapping, dan suhu simpan terhadap masa simpan, kekerasan, dan susut bobot buah jambu biji 'Crystal'

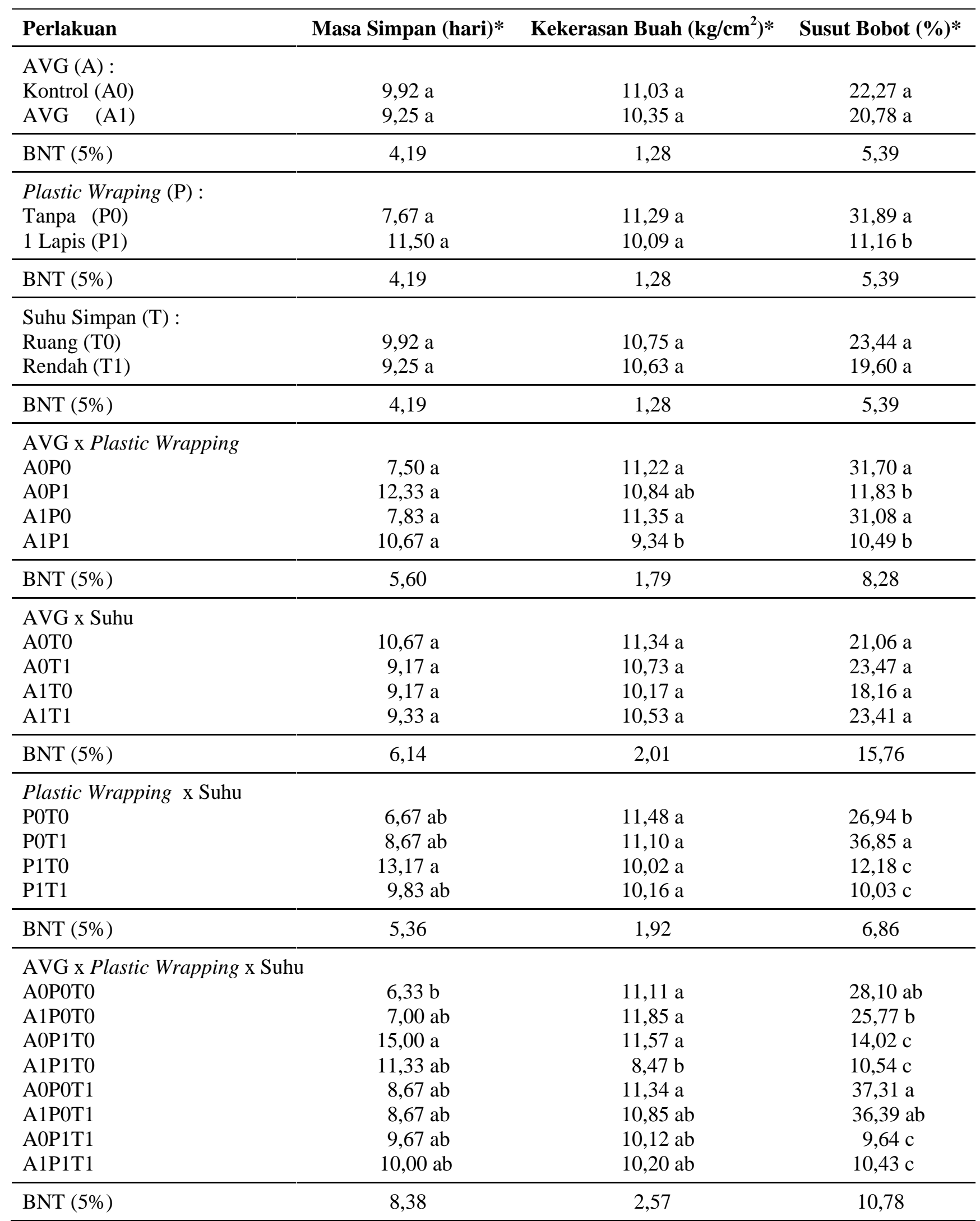

*Nilai sejalur yang diikuti dengan huruf yang sama tidak berbeda nyata menurut uji BNT 5\%; tingkat kekerasan buah pada 0 hari simpan adalah $14,57 \mathrm{~kg} / \mathrm{cm}^{2}$ 
stabil sehingga bertujuan untuk menunda pelunakan. Dalam penelitian ini, buah jambu biji 'Crystal' yang disimpan pada suhu rendah $21,53^{\circ} \mathrm{C}$ dengan kelembapan relatif sebesar $44,93 \%$ dan suhu ruang $26,87^{\circ} \mathrm{C}$ dengan kelembapan relatif sebesar 59,15\% memiliki masa simpan yang sama (Tabel 1). Diduga bahwa suhu 21,53 ${ }^{\circ} \mathrm{C}$ tidak efektif untuk penyimpanan buah jambu biji 'Crystal'. Islam et al. (2008) menyatakan bahwa suhu penyimpanan $5^{\circ} \mathrm{C}$ pada buah jambu biji mampu menahan kondisi buah sehingga masa simpan dapat ditingkatkan.

Berdasarkan Tabel 1, AVG ( $\left.\mathrm{A}_{1}\right)$, plastic wrapping $\left(\mathrm{P}_{1}\right)$, dan suhu rendah $\left(\mathrm{T}_{1}\right)$ tidak dapat menunda pelunakan pada buah (Tabel 1). Toan et al. (2009) menyatakan bahwa aplikasi pascapanen Retain AVG 0,95 g/L mampu memperpanjang masa simpan pisang 'Cavendish' selama 43,6 hari. Perlakuan AVG tidak mempengaruhi buah jambu biji diduga karena konsentrasi AVG (1,25 ppm) yang digunakan masih rendah sehingga gas etilen tetap berproduksi dan kekerasan buah tidak dapat dihambat. Akan tetapi, penggunaan AVG dengan konsentrasi yang tinggi kurang ekonomis dalam upaya penanggulangan pascapanen pada buah.

Penyimpanan pada suhu rendah $\left(\mathrm{T}_{1}\right)$ memberikan hasil yang tidak berbeda nyata dalam menjaga kekerasan buah dibandingkan pada suhu ruang $\left(\mathrm{T}_{0}\right)$ (Tabel 1). Hal ini diduga karena suhu rendah $21,53^{\circ} \mathrm{C}$ yang digunakan kurang efektif dalam menunda pelunakan buah sehingga diperlukan suhu yang lebih rendah. Bron et al. (2005) mengemukakan bahwa suhu $11^{\circ} \mathrm{C}$ mampu menekan laju respirasi dibandingkan suhu $21^{\circ} \mathrm{C}$. Iflah et al. (2012) menyatakan bahwa suhu lebih tinggi dapat memacu proses hidrolisis propektin dan pektin sehingga pelunakan buah terjadi lebih cepat.

Perlakuan tunggal plastic wrapping mempengaruhi susut bobot buah. Kehilangan air pada buah yang dilapisi dengan plastic wrapping mampu ditekan. Berdasarkan Tabel 1, susut bobot dapat dihambat secara nyata dengan perlakuan plastic wrapping $\left(\mathrm{P}_{1}\right)$ dibandingkan tanpa plastic wrapping (P0). Kombinasi dua perlakuan tanpa AVG dan plastic wrapping $\left(\mathrm{A}_{0} \mathrm{P}_{1}\right)$ serta $\mathrm{AVG}$ dan plastic wrapping $\left(\mathrm{A}_{1} \mathrm{P}_{1}\right)$ mampu mempengaruhi susut bobot buah dibandingkan dengan perlakuan lain. Hal ini diperkuat dengan penelitian sebelumnya oleh Widodo et al. (2013b) bahwa susut bobot buah jambu biji 'Crystal' dengan pengemasan 1 lapis plastic wrapping 11,3\% lebih rendah dibandingkan dengan tanpa plastic wrapping.

Plastic wrapping yang dikombinasikan dengan AVG (A1P1) atau tanpa AVG (A0P1) dan pada suhu ruang (P0T0) atau suhu rendah (P0T1) juga secara nyata mampu menghambat susut bobot pada buah (Tabel
1). Purwoko dan Suryana (2000) menyatakan bahwa proses transpirasi menyebabkan buah kehilangan bobot selama penyimpanan serta menurunkan mutu pada buah. Efek dari perlakuan tunggal plastic wrapping juga terlihat pada kombinasi perlakuan plastic wrapping dan suhu ruang $\left(\mathrm{P}_{1} \mathrm{~T}_{0}\right)$ serta plastic wrapping dan suhu rendah $\left(\mathrm{P}_{1} \mathrm{~T}_{1}\right)$ yang secara nyata dapat menunda penyusutan pada buah jambu biji 'Crystal' dibandingkan dengan perlakuan lain.

Efek tunggal plastic wrapping juga mempengaruhi perlakuan dengan tiga kombinasi (Tabel 1). Perlakuan tiga kombinasi dengan plastic wrapping berpengaruh nyata pada susut bobot, yaitu tanpa AVG, plastic wrapping dan suhu ruang $\left(\mathrm{A}_{0} \mathrm{P}_{1} \mathrm{~T}_{0}\right) ; \mathrm{AVG}$, plastic wrapping dan suhu ruang $\left(\mathrm{A}_{1} \mathrm{P}_{1} \mathrm{~T}_{0}\right)$; tanpa $\mathrm{AVG}$, plastic wrapping dan suhu rendah $\left(\mathrm{A}_{0} \mathrm{P}_{1} \mathrm{~T}_{1}\right)$; serta $\mathrm{AVG}$, plastic wrapping dan suhu rendah $\left(\mathrm{A}_{1} \mathrm{P}_{1} \mathrm{~T}_{1}\right)$. Keempat kombinasi perlakuan tersebut memiliki susut bobot yang rendah dibandingkan dengan kombinasi perlakuan lainnya. Rachmawati (2010) menyatakan kehilangan air pada suatu produk, terutama buah, dapat menyebabkan kehilangan bobot, pelunakan daging buah, dan penampilan atau mutu buah menjadi tidak menarik.

Pada Tabel 1, penyimpanan suhu rendah 21,53 ${ }^{\circ} \mathrm{C}$ dengan kelembapan relatif 44,93\% $\left(\mathrm{T}_{1}\right)$ tidak memberikan pengaruh yang nyata terhadap susut bobot pada buah jambu biji 'Crystal' dibandingkan dengan suhu ruang $26,87^{\circ} \mathrm{C}$ dengan kelembapan relatif $59,15 \%$. Hasil tersebut diduga karena suhu rendah tidak berpengaruh terhadap proses transpirasi yang menyebabkan susut bobot, tetapi hanya berpengaruh terhadap proses respirasi pada buah. Bron et al. (2005) menyatakan bahwa laju respirasi buah jambu biji pada penyimpanan suhu $11{ }^{\circ} \mathrm{C}$ lebih rendah dibandingkan dengan penyimpanan pada suhu $21^{\circ} \mathrm{C}$.

Pada Tabel 2, perlakuan plastic wrapping berpengaruh nyata terhadap ${ }^{\circ}$ Brix buah jambu biji 'Crystal'. Selama buah disimpan, proses pemasakan terus berjalan. Widodo et al. (2012) menyatakan bahwa pemasakan buah menyebabkan kandungan padatan terlarut meningkat. Terbukti dengan nilai ${ }^{\circ}$ Brix pada saat awal pengamatan adalah $10 \%$ (lihat keterangan pada Tabel 2) dan pada akhir pengamatan berkisar antara $12,77-18,53 \%$. Hal ini diduga terjadi karena adanya perombakan pati pada saat respirasi menjadi gula.

Selama penyimpanan, asam bebas pada buah jambu biji 'Crystal' menurun. Hal ini terbukti dengan nilai asam bebas pada awal pengamatan adalah $0,92 \mathrm{~g} /$ $100 \mathrm{~g}$ (lihat keterangan pada Tabel 2), sedangkan pada akhir pengamatan berkisar antara 0,31-0,51 g/100 g. Bari et al. (2006) menyatakan bahwa pada tingkat kematangan awal, total asam akan meningkat lalu 
Tabel 2. Pengaruh AVG, plastic wrapping, dan suhu simpan terhadap ${ }^{\circ}$ Brix, asam bebas dan tingkat kemanisan buah jambu biji 'Crystal'

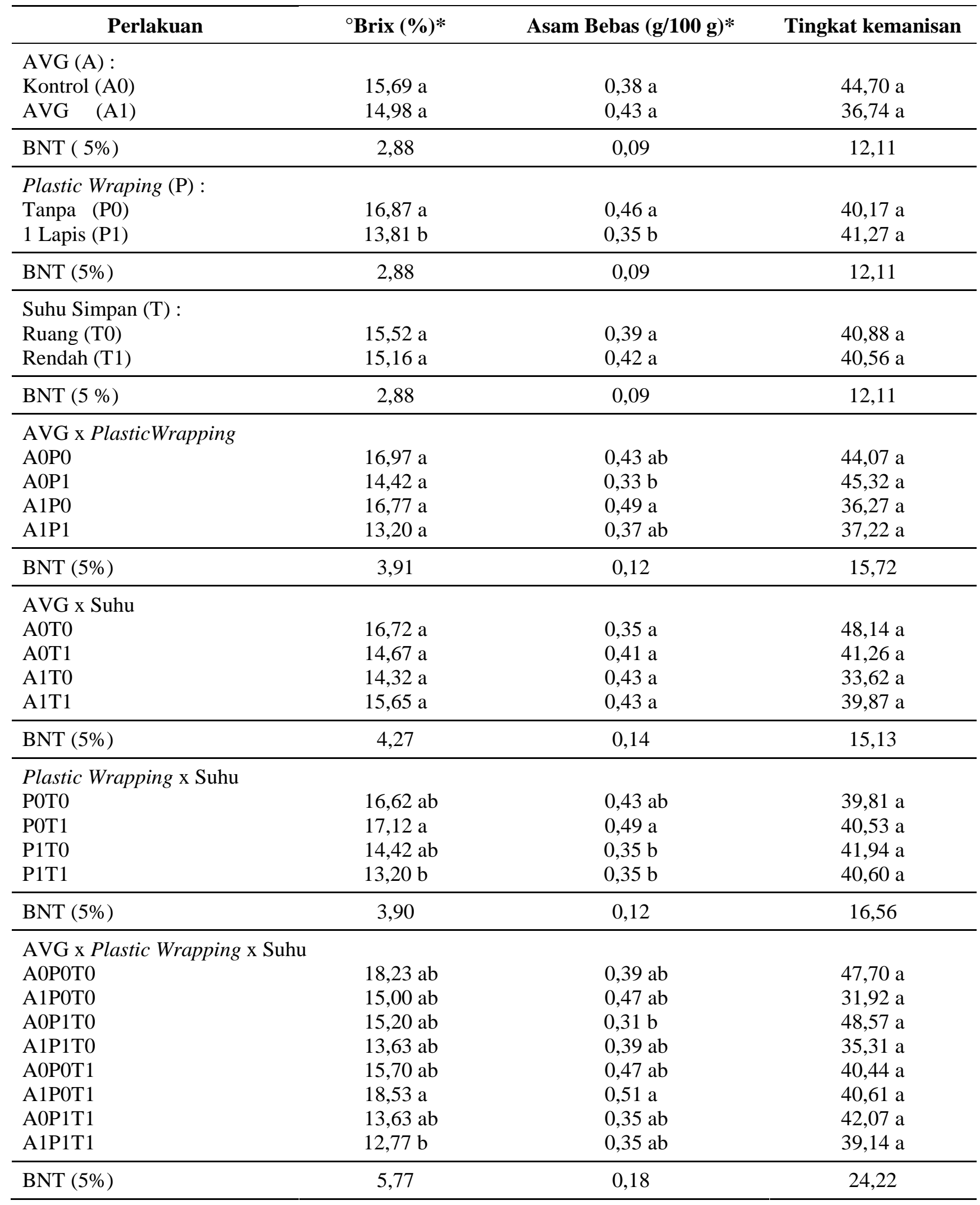

*Nilai sejalur yang diikuti dengan huruf yang sama tidak berbeda nyata menurut uji BNT 5\%; nilai ${ }^{\circ}$ Brix, asam bebas, dan tingkat kemanisan pada 0 hari simpan adalah $10 \%, 0,93 \mathrm{~g} / 100 \mathrm{~g}, 11,66$; tingkat kemanisan adalah nisbah ${ }^{\circ}$ Brix dan asam bebas. 
menurun pada saat buah akan membusuk. Novita et al. (2012) menyatakan bahwa nilai total padatan terlarut pada buah tomat selama proses pematangan buah akan terus meningkat, yang disebabkan oleh degradasi pati (karbohidrat) menjadi gula sederhana (glukosa dan fruktosa).

Suhu rendah tidak mempengaruhi total padatan terlarut pada buah jambu biji 'Crystal' (Tabel 2). Augustin dan Osman (1988) menyatakan bahwa total padatan terlarut pada buah jambu biji tidak berbeda nyata setelah disimpan pada suhu ruang dan pada suhu rendah. Adirahmanto et al. (2013) menyatakan bahwa penyimpanan buah salak pada suhu ruang dan suhu rendah $\left(106-12{ }^{\circ} \mathrm{C}\right)$ tidak memperlihatkan pengaruh yang nyata pada nilai total padatan terlarut. Pada Tabel 2 , tingkat kemanisan tidak berbeda nyata dengan semua perlakuan yang diterapkan. Widodo et al. (2012) menyatakan bahwa total padatan terlarut, asam bebas dan tingkat kemanisan tidak berbeda nyata pada buah yang dihentikan pada tingkat kemasakan yang sama.

\section{KESIMPULAN}

Hasil penelitian menunjukkan bahwa aplikasi AVG tidak mampu meningkatkan masa simpan, kekerasan, susut bobot, ${ }^{\circ}$ Brix, asam bebas, dan kemanisan pada buah jambu biji 'Crystal. Aplikasi plastic wrapping mampu menekan susut bobot, tetapi tidak mampu meningkatkan masa simpan, mempertahankan kekerasan, ${ }^{\circ}$ Brix, asam bebas, dan tingkat kemanisan buah jambu biji 'Crystal'. Penyimpanan suhu rendah tidak mampu meningkatkan masa simpan, kekerasan, susut bobot, ${ }^{\circ}$ Brix, asam bebas, dan kemanisan pada buah jambu biji 'Crystal' dan tidak terdapat interaksi antara AVG, plastic wrapping dan suhu rendah dalam meningkatkan masa simpan dan mempertahankan kekerasan, susut bobot, ${ }^{\circ}$ Brix, asam bebas, dan kemanisan pada buah jambu biji 'Crystal'.

\section{SANWACANA}

Ucapan terima kasih ditujukan kepada Direktorat Jendral Penguatan Riset dan Pengembangan, Kementerian Riset, Teknologi, dan Pendidikan Tinggi Republik Indonesia yang telah membiayai penelitian ini melalui Hibah Kompetensi tahun 2014. Selain itu, ucapan terima kasih juga ditujukan kepada PT. Nusantara Tropical Farm (PT. NTF), Way Jepara, Lampung Timur, atas bantuan pengadaan sampel buah jambu biji ‘Crystal' dan Ir. Tri Dewi Andalasari, M.Si atas diskusi dan saran selama penyusunan laporan penelitian.

\section{DAFTAR PUSTAKA}

Adirahmanto, K. A., R. Hartanto, dan D. D. Novita. 2013. Perubahan kimia dan lama simpan buah salak pondoh (Salacca edulis REINW) dalam penyimpanan dinamis udara- $\mathrm{CO}_{2}$. J. Teknik Pert. Lampung. 2(3):123-132

Augustin, M. A., dan A. Osman. 1988. Post-harvest storage of guava (Psidium guajava $\mathrm{L}$, var Taiwan). Pertanika. 11(1): 45-50.

Bari, L., P. Hasan., N. Absar, M. E. Haque, M. I. I. E. Khuda, M. M. Pervin, S. Khatun, dan M. I. Hossain. 2006. Nutritional analysis of two local varieties of papaya (Carica papaya L.) at different maturation stages. Pakistan J. Biol. Sci. 9(1): 137-140.

Bron, I. U., R. V. Ribeiro, F. C. Cavalini, A. P. Jacomino, dan M. J. Trevisan. 2005. Temperature-related changes in respiration and $Q_{10}$ coefficient of guava. Sci. Agric. (Piracicaba, Braz.) 62(5): 458-463.

Cetinbas, M. dan F. Koyuncu. 2011. Effects of aminoethoxyvinylglycine on harvest time and fruit quality of 'Monroe' peaches. J. Agric. Sci. 17: 177189.

Iflah, T., Sutrisno, dan T. C. Sunarti. 2012. Pengaruh kemasan starch-based plastics (bioplastik) terhadap mutu tomat dan paprika selama penyimpanan dingin. J. Teknol. Ind. Pert. 22(3):189-197.

Islam, F., A. Islam, M. A. Z. A. Al Munsur, dan M. A. Rahim. 2008. Shelf life and quality of guava cv. Kazi as affected by stages of ripening, storage temperature and wrapping materials. Progress. Agric. 19(2): 1-12.

Novita, M., Satriana, Martunis, S. Rohaya, dan E. Hasmarita. 2012. Pengaruh pelapisan kitosan terhadap sifat fisik dan kimia tomat segar (Lycopersicum pyriforme) pada berbagai tingkat kematangan. J. Teknol. Ind. Pert. Indonesia. 4(3): 1-8.

Purwoko, B. S. dan K. Suryana. 2000. Efek suhu simpan dan pelapis terhadap kualitas buah pisang Cavendish. Bul. Agron. 28(3): 77-84 
Rachmawati, M. 2010. Pelapisan chitosan pada buah salak pondok (Salacca edulis Reinw) sebagai upaya memperpanjang umur simpan dan kajian sifat fisiknya selama penyimpanan. J. Teknol. Pert. 6(2): 45-49.

Tarabih, M. E. 2014. Improving storability of Le Conte pear fruit using aminoethoxyvinylglycine $(A V G)$ and oxalic acid $(O A)$ under cold storage conditions. Asian J. Crop Sci. 6(4): 320-333.

Teixeira, G. H. A. dan J. F. Durigan. 2010. Effect of controlled atmospheres with low oxygen levels on extended storage of guava fruit (Psidium guajava L. 'Pedro Sato'). HortSci. 45(6): 918924.

Toan, N. V., L. V. Hoang, L. V Tan, L. T. L. Thanh, C. D. Thanh, dan T. M. Hanh. 2009. Effects of Retain - AVG (aminoethoxyvinylglycine) on the storage time of banana (Musa Cavendish AAA) after harvest. Tap Chi Khoa Hoc Va Cong Nghe Tap. 47 (1): 27-33.
Utama, I. M. S., K. A. Nocianitri, dan F. W. Tunggadewi. 2006. Mempelajari pengaruh ketebalan plastik film polietilen densitas rendah sebagai bahan kemasan buah manggis terhadap modifikasi gas oksigen dan karbondioksida. J. Agritrop. 25(1): 1-11.

Widodo, S. E., Zulferiyenni, dan D. W. Kusuma. 2013a. Pengaruh penambahan benziladenin pada pelapis kitosan terhadap mutu dan masa simpan buah jambu biji 'Crystal'. J. Agrotek Trop. 1(1):55-60.

Widodo, S. E., Zulferiyenni, dan I. Maretha. 2012. Pengaruh penambahan indole acetic acid pada pelapis kitosan terhadap mutu dan masa simpan buah jambu biji (Psidium guajava L.) 'Crystal'. J. Agrotrop. 17(1): 14-18.

Widodo, S. E., Zulferiyeni, dan R. Arista. 2013b. Coating effect of chitosan and plastic wrapping on the self-life and qualities of 'Mutiara' and 'Crystal' guavas. J. ISSAAS. 19(1): 1-7. 